Supporting information

\title{
A dual function antimicrobial loaded lectin carrier: a strategy to overcome biomolecular interference without resistance
}

Siva Bala Subramaniyan, Subburethinam Ramesh, Rajendran Senthilnathan, Veerappan Anbazhagan*

Department of Chemistry, School of Chemical \& Biotechnology, Shanmugha Arts, Science, Technology \& Research Academy (SASTRA) Deemed University, Thanjavur - 613401, Tamil Nadu, India.
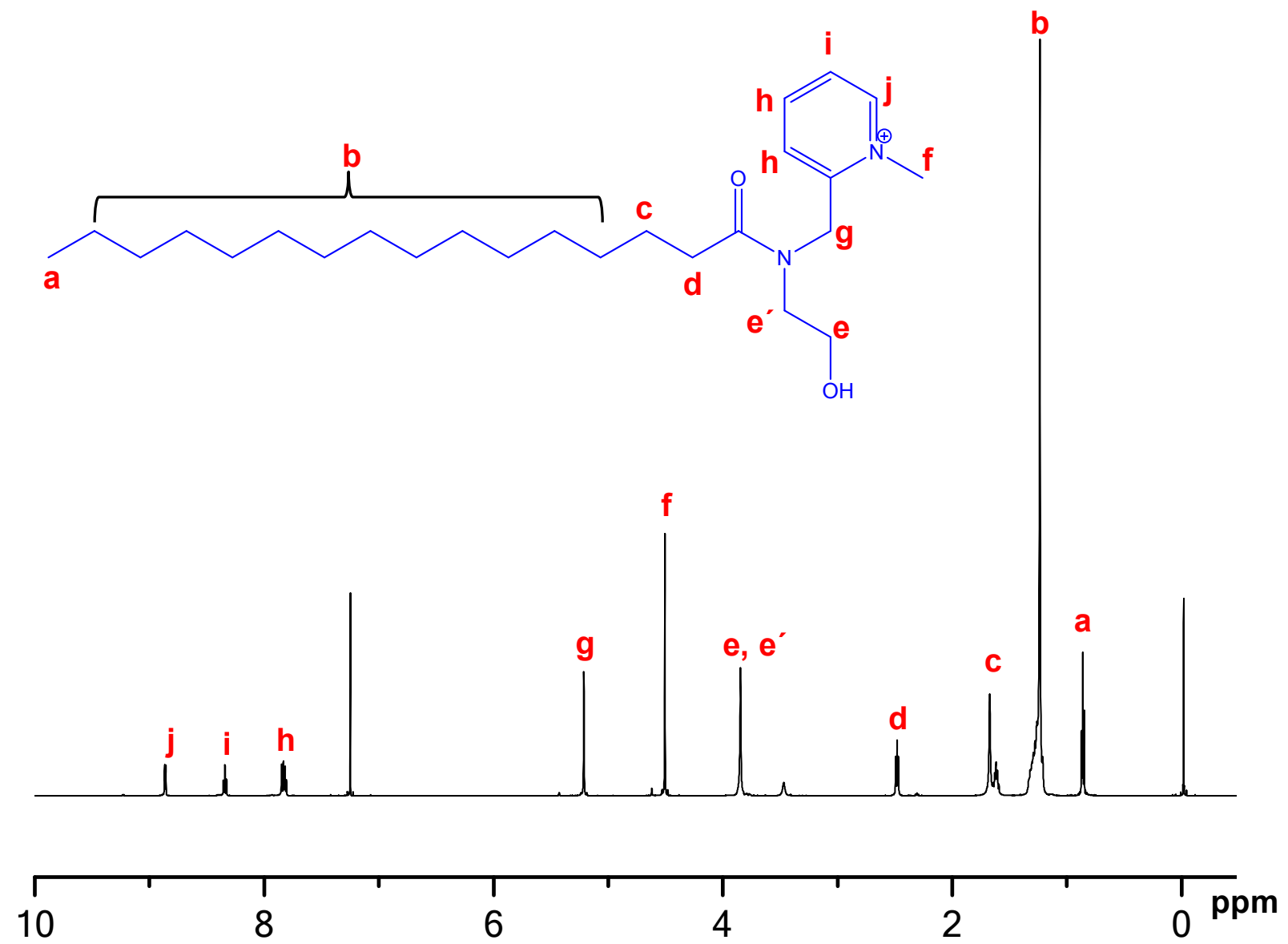

Fig. S1: ${ }^{1} \mathrm{H}$ NMR spectra of 2-((N-(2-hydroxyethyl)tetradecanamido)methyl)-1-methylpyridin-1ium iodide (cN16E). ${ }^{1} \mathrm{H}$ NMR (600 MHz, $\left.\mathrm{CDCl}_{3}\right)$ : $8.86(1 \mathrm{H}, \mathrm{d}), 8.34(1 \mathrm{H}, \mathrm{t}), 7.85-7.80(2 \mathrm{H}, \mathrm{m})$, $5.20(2 \mathrm{H}, \mathrm{s}), 4.51(3 \mathrm{H}, \mathrm{m}), 3.85(4 \mathrm{H}, \mathrm{bs}), 2.48(2 \mathrm{H}, \mathrm{t}), 1.67-1.59(2 \mathrm{H}, \mathrm{m}), 1.30-1.22(20 \mathrm{H}, \mathrm{m})$, $0.86(3 \mathrm{H}, \mathrm{t})$. 


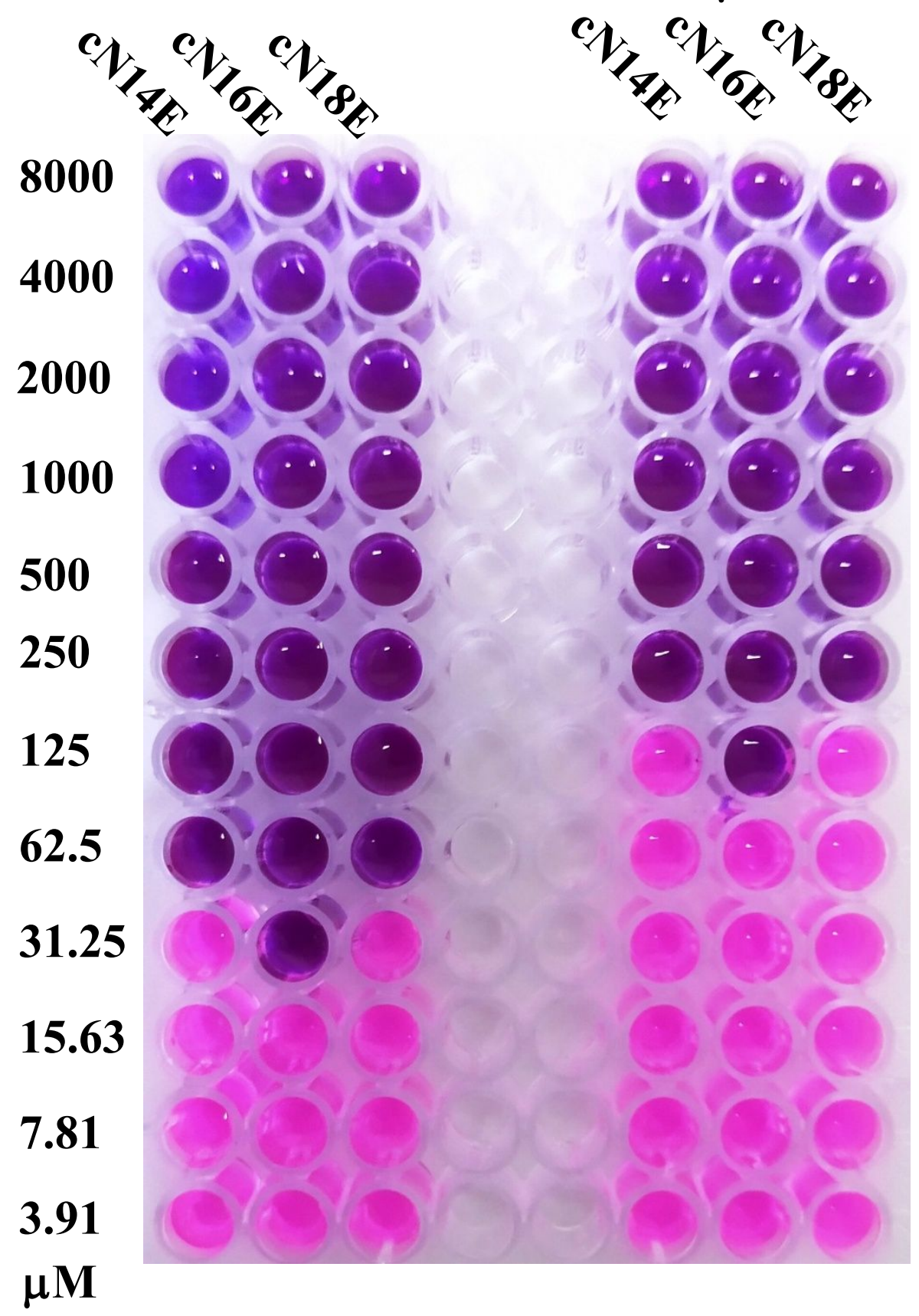

Fig. S2: Determination of minimum inhibitory concentration by REMA. Blue colour indicates non-respiratory cells and pink colour viable cells. A color change from blue to pink was considered as MIC. 


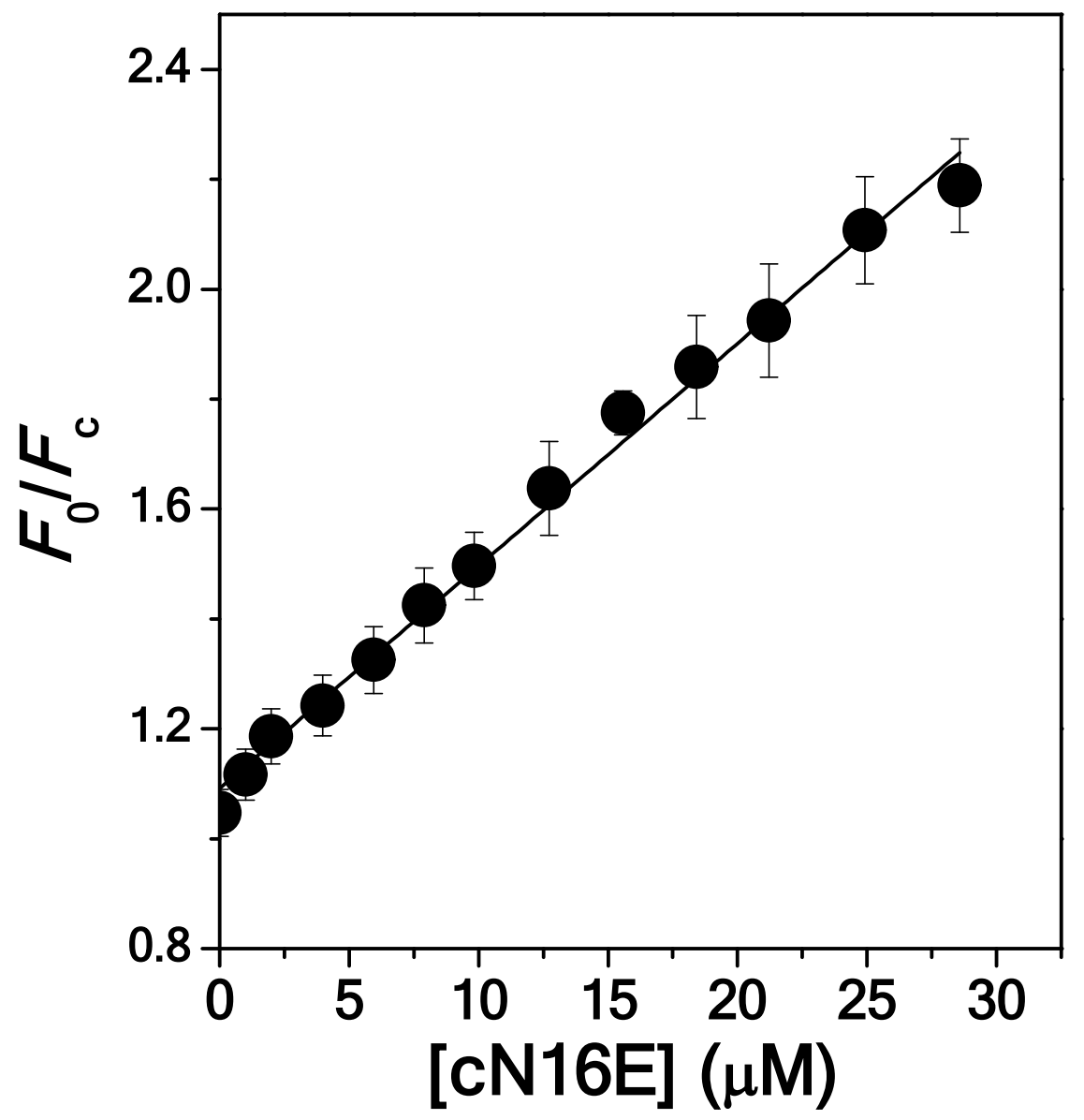

Fig. S3: Stern-Volmer plot. The fluorescence data was analyzed by Stern-Volmer equation: $F_{0} / F_{\mathrm{c}}$ $=1+K_{\mathrm{sv}}[\mathrm{cN1} 16 \mathrm{E}]=1+K_{\mathrm{q}} \tau_{0}[\mathrm{cN} 16 \mathrm{E}]$, where $K_{\mathrm{q}}=K_{\mathrm{sv}} / \tau_{0} . K_{\mathrm{sv}}$ is the Stern-Volmer quenching constant, $\quad K_{\mathrm{q}}$ is the biomolecular quenching constant, and $\tau_{0}$ is the average fluorescence lifetime of BSA (5 ns). From the linear Stern-Volmer plot, $K_{\mathrm{sv}}\left(2.42 \times 10^{4} \mathrm{M}^{-1}\right)$ was determined. The $K_{\mathrm{q}}\left(4.84 \times 10^{12} \mathrm{~L} / \mathrm{mol} \mathrm{s}\right)$ calculated for the BSA-cN16E interaction was higher than the $K_{\mathrm{q}}$ $\left(10^{10} \mathrm{~L} / \mathrm{mol} \mathrm{s}\right)$ obtained for the diffusion-controlled quenching process. These results suggest that the quenching process is static and a non-fluorescent complex is likely formed between BSA and cN16E. 

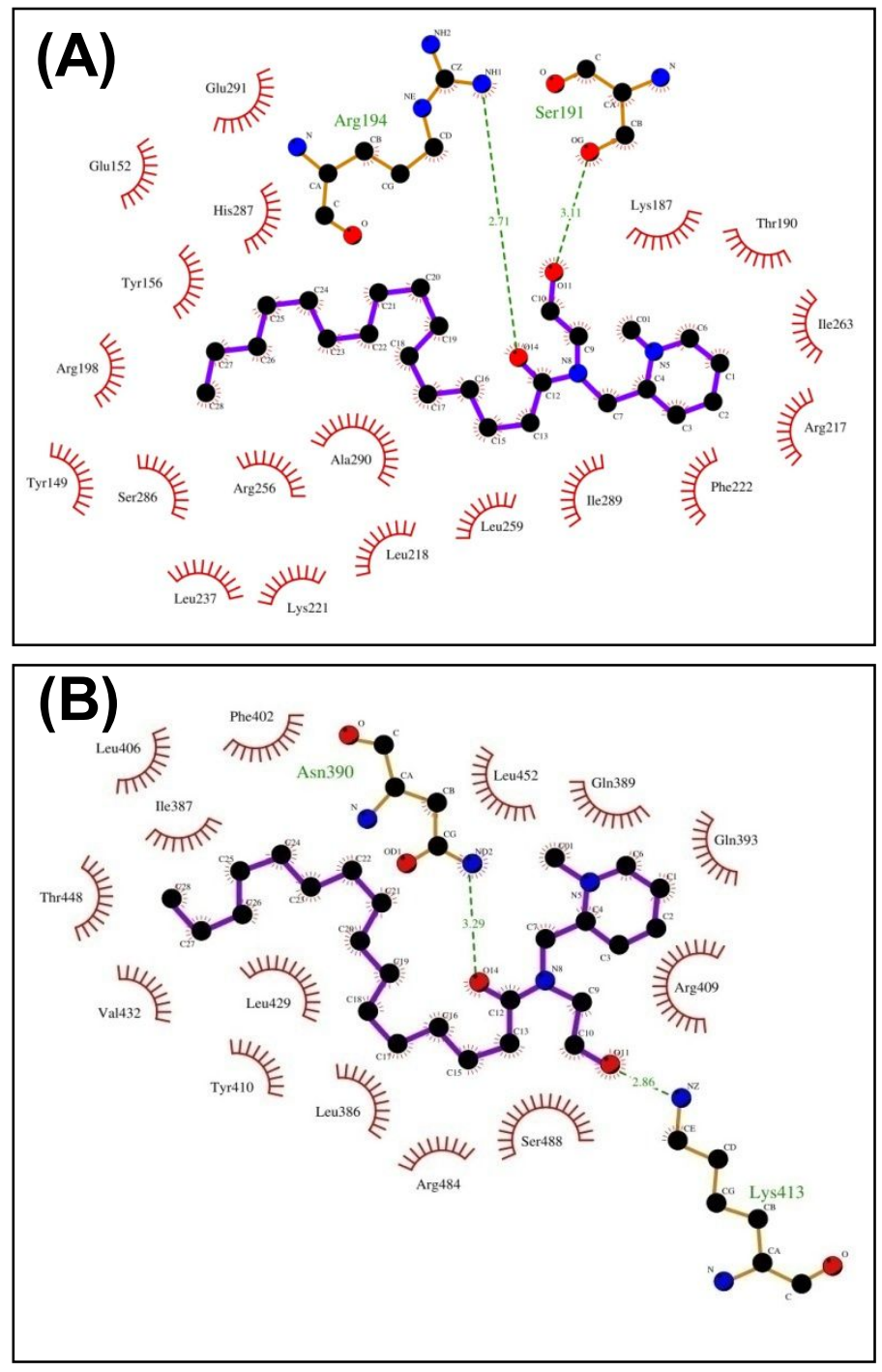

Fig. S4: Molecular docking. Docking result was shown as Ligplot, (A) BSA binding site I and (B) Site II. cN16E was shown in ball-stick model. H-bond is shown in dotted line, and the residues of BSA involved in hydrophobic interactions are presented. 

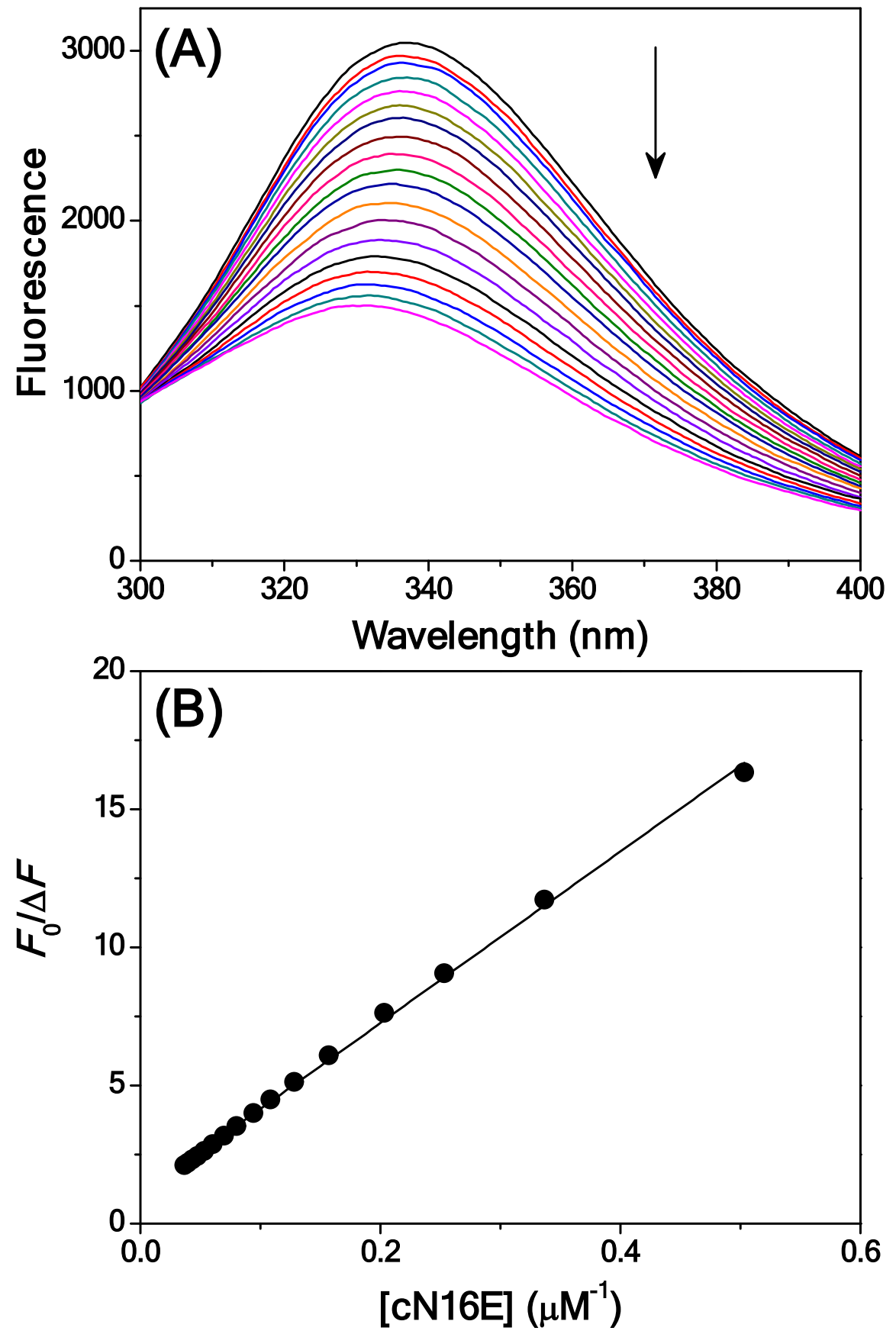

Fig. S5: Interaction of BMSL with cN16E. (A) Fluorescence titration. The first spectrum corresponds to free BMSL and the remaining spectra with decreasing fluorescence emission were obtained in the presence of increasing cN16E concentrations. (B) Modified Stern-Volmer plot. The experiments are performed in triplicate. 

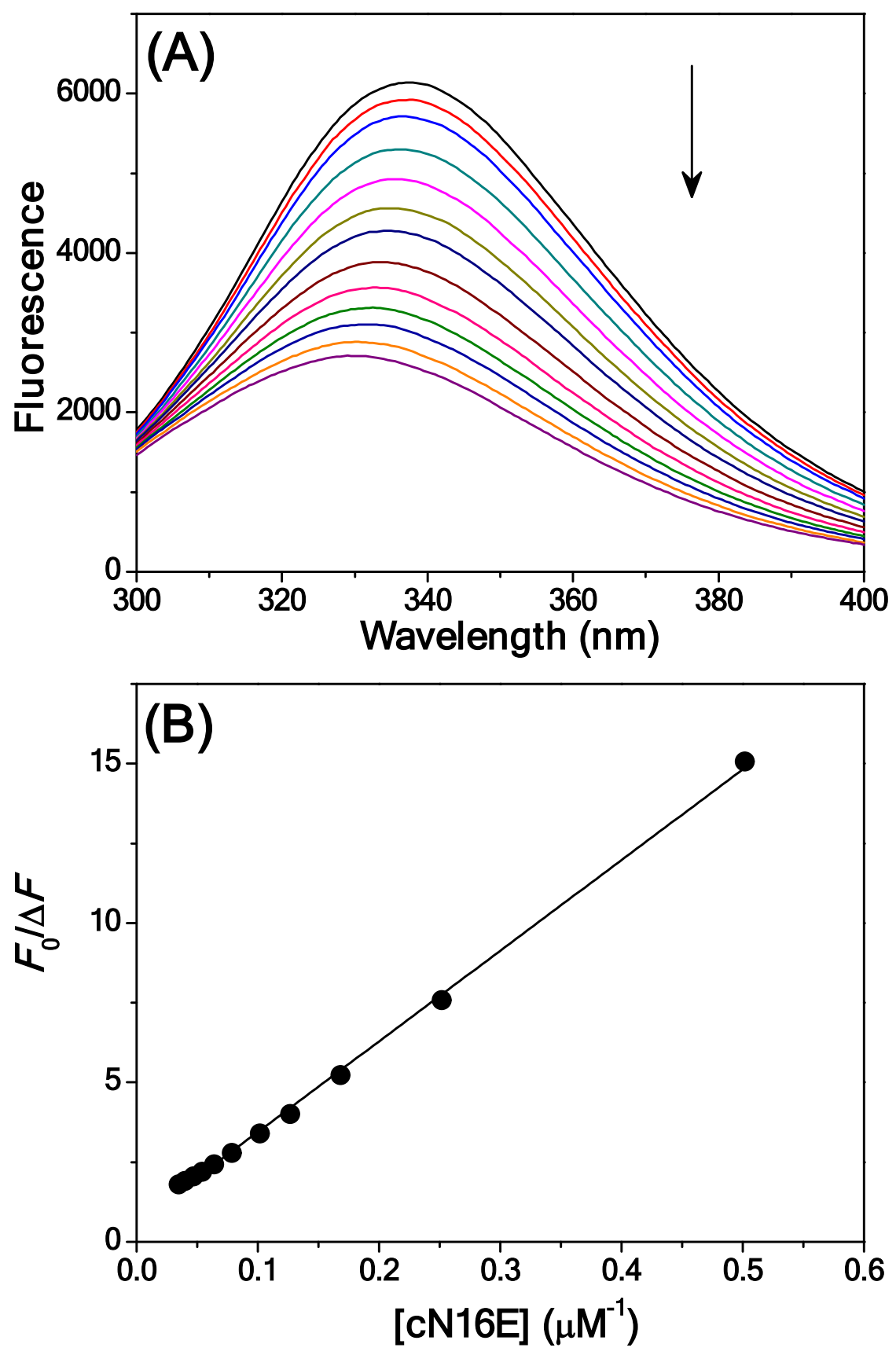

Fig. S6: Interaction of BMSL with $\mathrm{cN16E}$ in the presence of $100 \mathrm{mM}$ galactose. (A) Fluorescence titration. The first spectrum corresponds to BMSL with $100 \mathrm{mM}$ galactose and the remaining spectra with decreasing fluorescence emission were obtained in the presence of increasing $\mathrm{cN} 16 \mathrm{E}$ concentrations. Prior to the titration BMSL was incubated with $100 \mathrm{mM}$ galactose at $4^{\circ} \mathrm{C}$ for $2 \mathrm{~h}$. (B) Modified Stern-Volmer plot. 


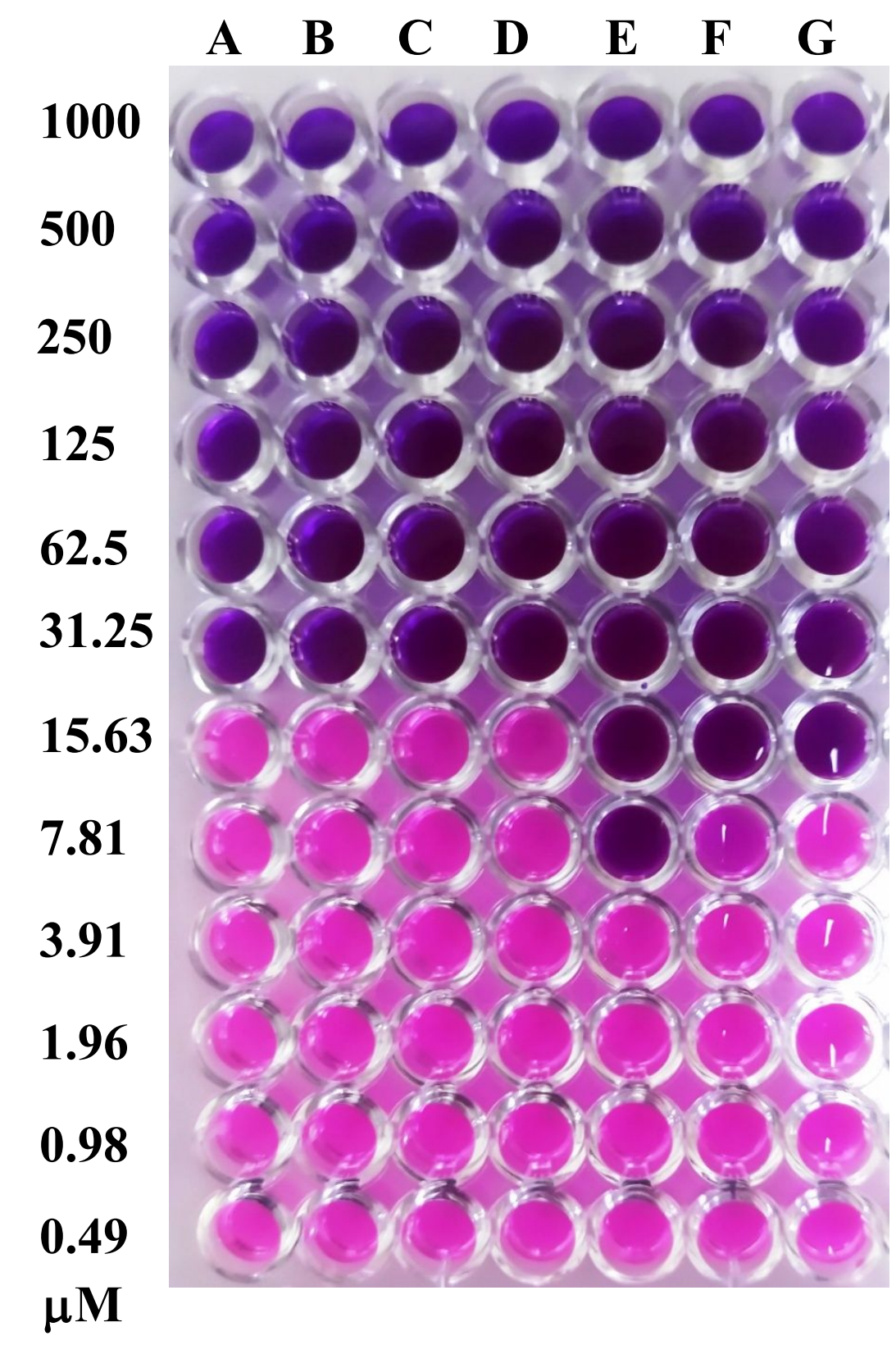

Fig. S7: Effect of BMSL on the MIC of cN16E. UPEC cells were exposed to various concentrations of $\mathrm{cN} 16 \mathrm{E}$ in the presence of fixed concentration of BMSL. The concentration of BMSL increases from Lane 2 to Lane 7, $(10,20,30,50,100,200 \mu \mathrm{M})$. It is noted that the MIC of cN16E decreases significantly in the presence of BMSL. The lowest MIC $(7.81 \mu \mathrm{M})$ was obtained from $50 \mu \mathrm{M}$ of BMSL. It is noted that above $50 \mu \mathrm{M}$ BMSL, MIC does not improved. Thus, $50 \mu \mathrm{M}$ BMSL was selected for the study. 


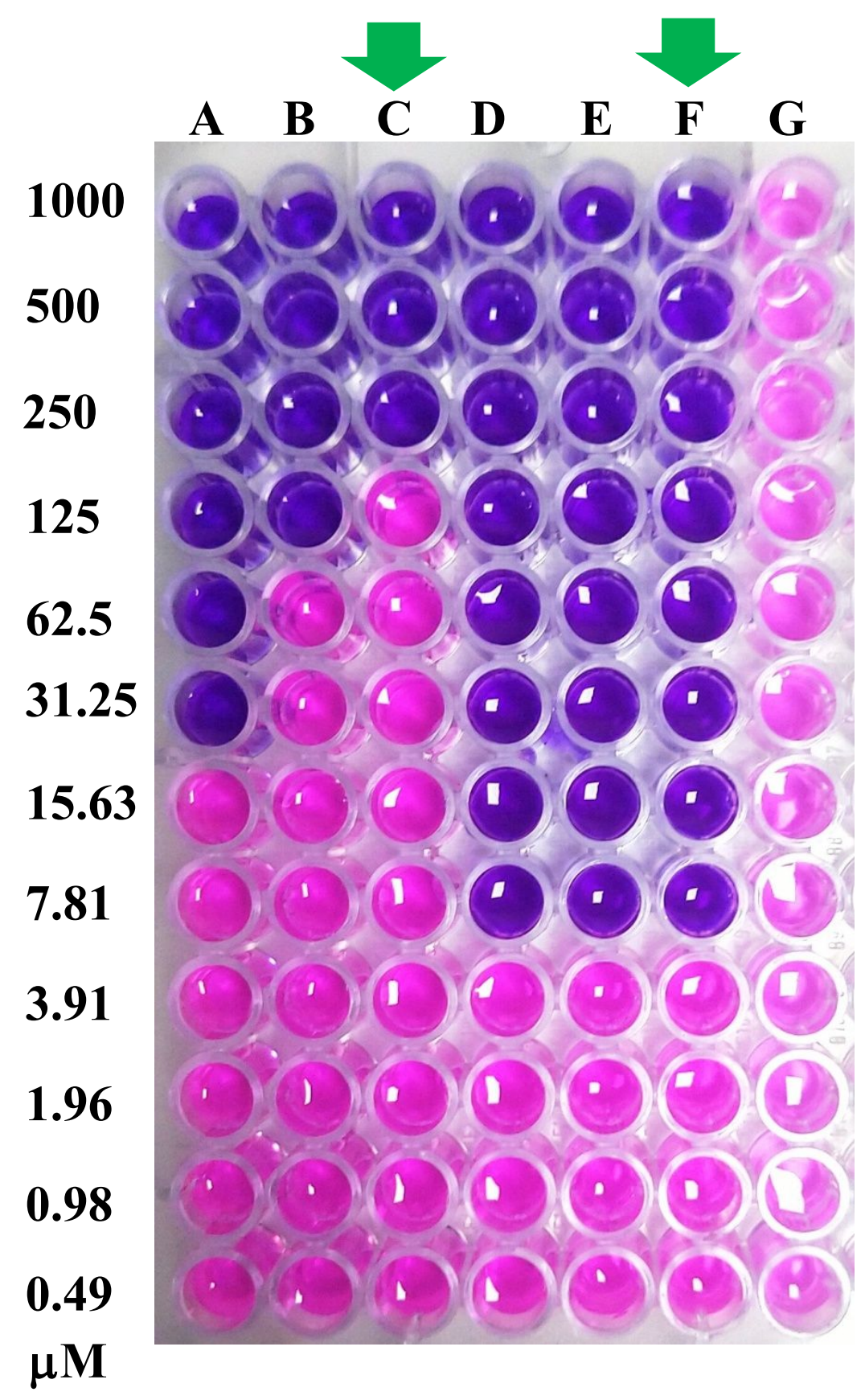

Fig. S8: Determination of MIC by REMA, A - cN16E; B - cN16E + $50 \mu \mathrm{M}$ BSA; C - cN16E + $50 \mu \mathrm{L}$ serum; $\mathrm{D}-\mathrm{cN} 16 \mathrm{E}+50 \mu \mathrm{M}$ BMSL; $\mathrm{E}-\mathrm{cN16 \textrm {E }}+50 \mu \mathrm{M}$ BMSL $+50 \mu \mathrm{M}$ BSA; F $\mathrm{cN16E}+50 \mu \mathrm{M}$ BMSL $+50 \mu \mathrm{L}$ serum; G - $50 \mu \mathrm{M}$ BMSL. Arrow the MIC obtained with serum. The color change from blue to pink is considered as MIC. It is noted from lane G, BMSL has no antimicrobial activity. 


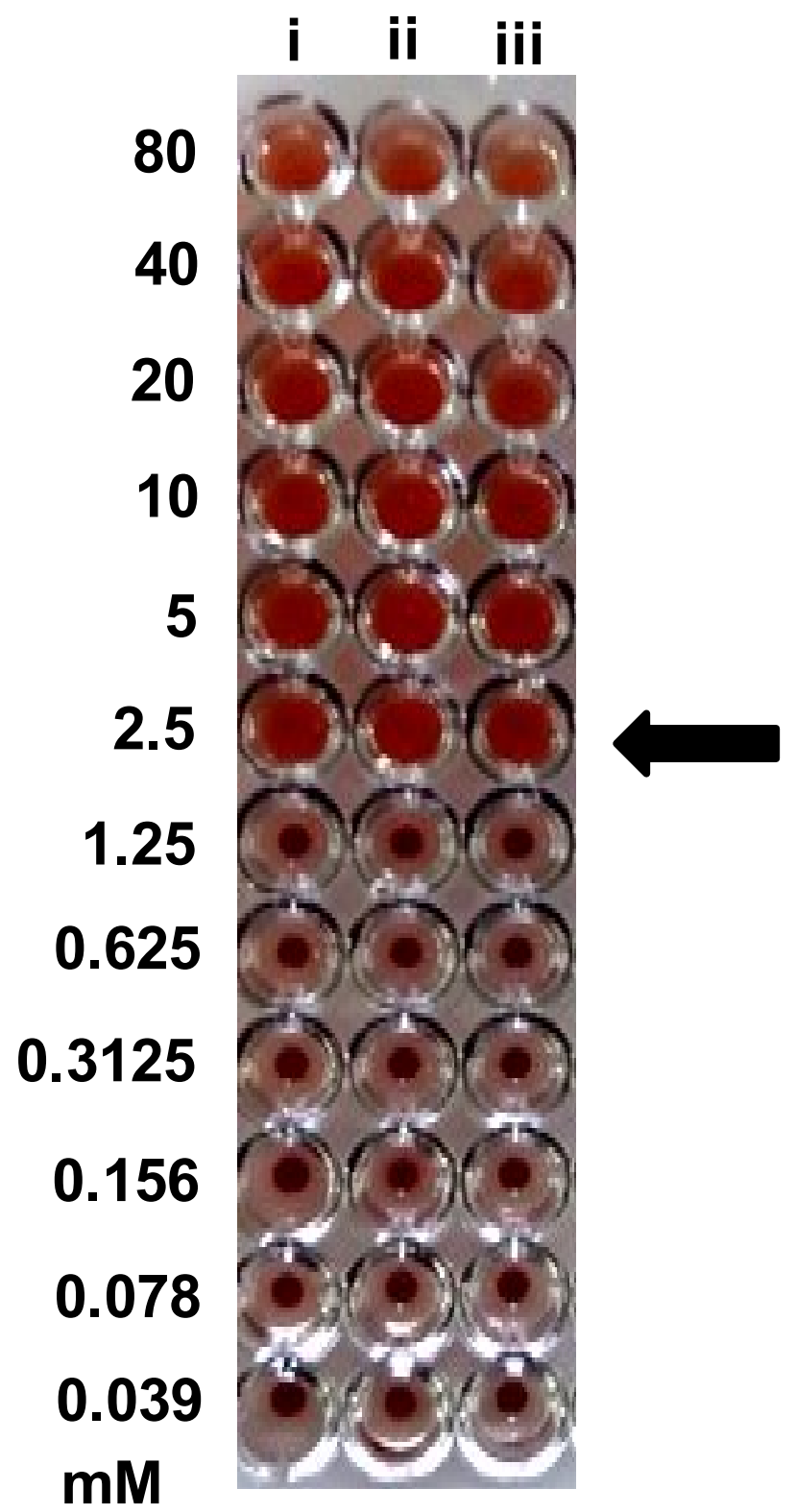

Fig. S9: Haemolysis assay. Human RBC was treated with various concentration of cN16E. Cells are lysed at $2.5 \mathrm{mM}$. Experiments were performed in triplicate. 

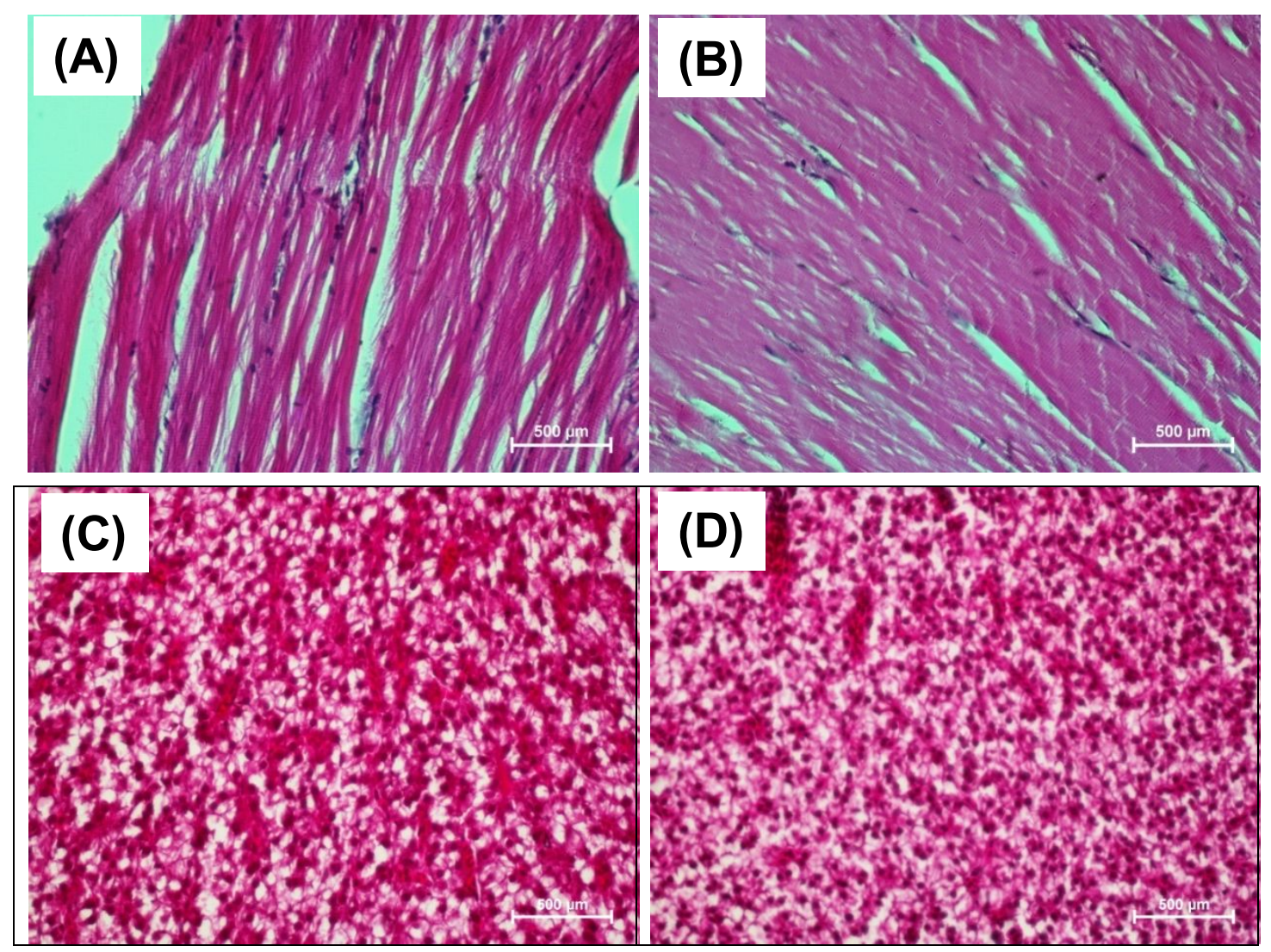

Fig. S10: Histology. Muscle of zebrafish injected with $10 \mu \mathrm{L}$ of (A) control, PBS, and (B) 1.25 $\mathrm{mM}$ cN16E. Liver of zebrafish injected with (A) control, PBS, and (B) $1.25 \mathrm{mM} \mathrm{cN16E}$. 
Infected control

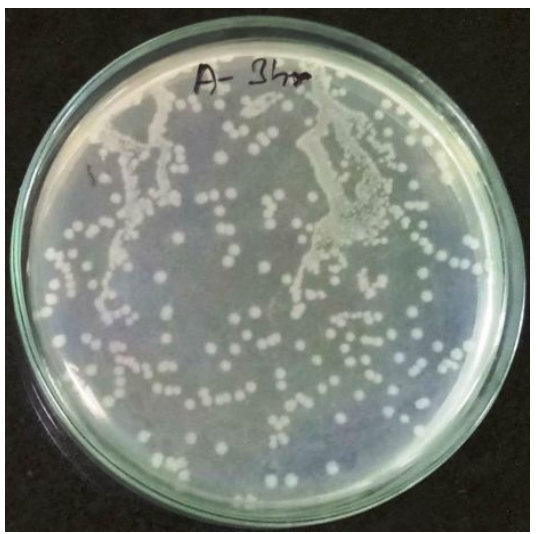

$4.46 \times 10^{8} \mathrm{cfu} / \mathrm{mL}$

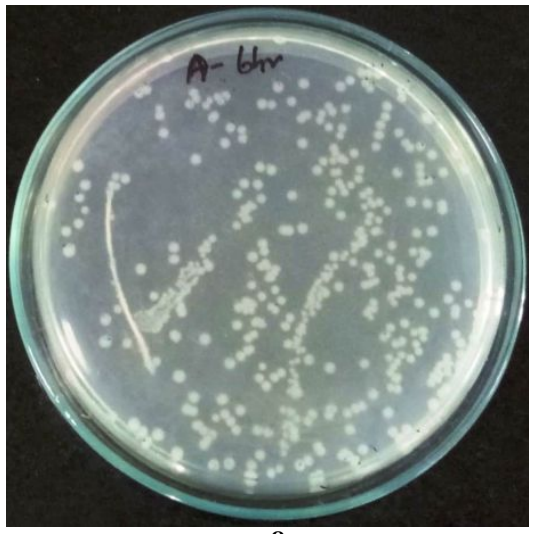

$6.34 \times 10^{8} \mathrm{cfu} / \mathrm{mL}$

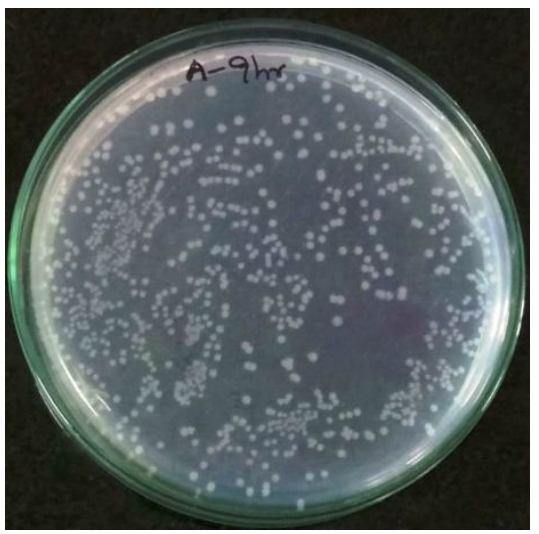

$16.04 \times 10^{8} \mathrm{cfu} / \mathrm{mL}$
Treated with

31.25 $\mu \mathrm{M}$ cN16Es

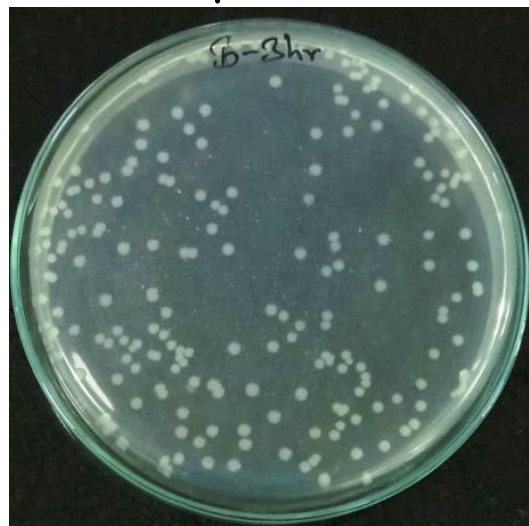

$4.02 \times 10^{8} \mathrm{cfu} / \mathrm{mL}$

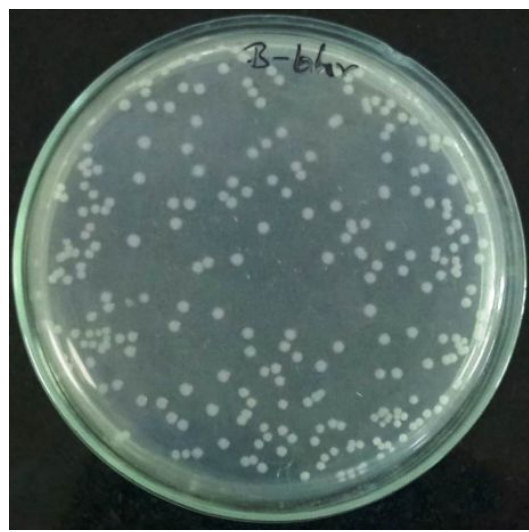

$7.12 \times 10^{8} \mathrm{cfu} / \mathrm{mL}$

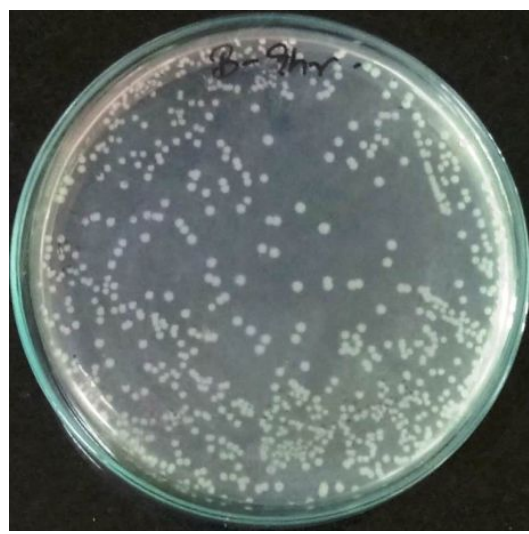

$16.66 \times 10^{8} \mathrm{cfu} / \mathrm{mL}$
Time

(h)

3

6

\section{9}

Fig. S11: Treatment with cN16E. UPEC infected fish were treated with $10 \mu \mathrm{L}$ of $31.25 \mu \mathrm{M}$ cN16E. Muscle tissue was dissected at the reported time point and homogenized and plated on the sterile LB agar plates. No fish are alive after $10 \mathrm{~h}$. 